\title{
D-Zero
}

\section{Run 2B Be Beam Pipe Assembly Preparation Information}

\section{D-ZERO ENGINEERING NOTE \# 3823.112-EN-580}

February 17, 2006

Author: Russell A. Rucinski

Project Engineer

PPD/MD/D0 Operations 


\section{D-Zero Run 2B beam pipe preparation information}

The D-Zero run $2 \mathrm{~B}$ beam pipe assembly will replace the currently installed run $2 \mathrm{~A}$ beryllium pipe during installation of the layer 0 silicon detector. The assembly (drg. 3823.210-ME-399403 rev. A) consists of a 1.0" dia. x 72.0" long beryllium beam pipe (drg. 3823.110-MD-399365) mated to two 12.25" long extension pieces (drg. 3823.210ME-399399) attached to each end. This engineering note documents the work done in certifying and validating these high vacuum components for use in the Tevatron beam pipe vacuum system.

\section{Executive Summary:}

The Run $2 \mathrm{~B}$ beam pipe assembly is leak tight and conditioned so that it will provide minimal gas load in the Tevatron beam pipe vacuum system. It has been characterized and the information documented so that others can independently reach the same conclusion. The preparation included leak check, vacuum baking, rate of rises, and residual gas analysis.

\section{Summary}

The beam pipe assembly is leak tight. The assembly was covered with a plastic bag and flooded with helium. No response was seen with a DuPont leak detector on the $\mathrm{x} 1$ scale and a sensitivity of $4 \times 10^{-10} \mathrm{~atm}-\mathrm{cc} / \mathrm{sec}$.

The beryllium beam pipe was previously vacuum baked to $300 \mathrm{C}$ and helium leak checked by the manufacturer, Brush Wellman Electrofusion, prior to its shipment to Fermilab in 2003. After arrival, it was helium leak checked by Particle Physics Division personnel and found to be leak tight. The beam pipe extensions were made at Fermilab in summer/fall 2005. They were leak checked and recently baked to $350 \mathrm{C}$ at Fermilab. The assembled section was baked to $105 \mathrm{C}$ for 28 hours. After cooling, the assembly reached an ultimate pressure of $1.2 \times 10^{-8}$ Torr measured at the non-pump end. This ultimate pressure is believed to be limited by the ultimate of the dry turbo pump cart (1.0 $\times 10^{-9}$ Torr) and pumping speed/conductance of the pumping path (tee, right angle metal seal valve, 1 meter flex hose, right angle valve, turbomolecular pump throat).

A rate of rise was done after the bake out and 84 hours of pumping to assess the outgassing rate. It took 40 minutes for the pressure to rise from $2.1 \times 10^{-8}$ Torr to $1.0 \mathrm{x}$ $10^{-9}$ Torr. This yields a very low calculated outgassing rate of $9 \times 10^{-14} \mathrm{Torr}-\mathrm{L} / \mathrm{s}-\mathrm{cm}^{2}=$ $1 \times 10^{-10} \mathrm{~W} / \mathrm{m}^{2}$. This value compares favorably to values given for metal high vacuum components.

A residual gas analysis (RGA) was performed on the beam pipe assembly. Peaks indicate contributions from water (18), carbon monoxide (28) and carbon dioxide. Peaks at $\mathrm{CO}(28)$ and $\mathrm{CO} 2$ (44) are attributed to the RGA filament itself. The results of the RGA are reasonable and do not indicate anything of concern. 


\section{Details in chronological order}

The work was done by PPD/MD/Vacuum group at Proton Assembly building. Ron Davis was the technical specialist in charge with support from Mark Ruschman and guidance from Cary Kendziora the group leader of the vacuum and instrumentation group. Russ Rucinski was the responsible engineer. Jim Fagan also participated in the work. Bill Cooper, leader of layer 0 mechanical installation, gave guidance, oversight and opinions at a senior level. The work took place in January and February 2006. Day to day activities and data are recorded on pages 55 thru 69 in a log book retained by Ron Davis. I gratefully acknowledge the careful work and expertise of Ron Davis in carrying out this work. Mark Ruschman also needs to get special mention for the data acquisition system and assistance on the project.

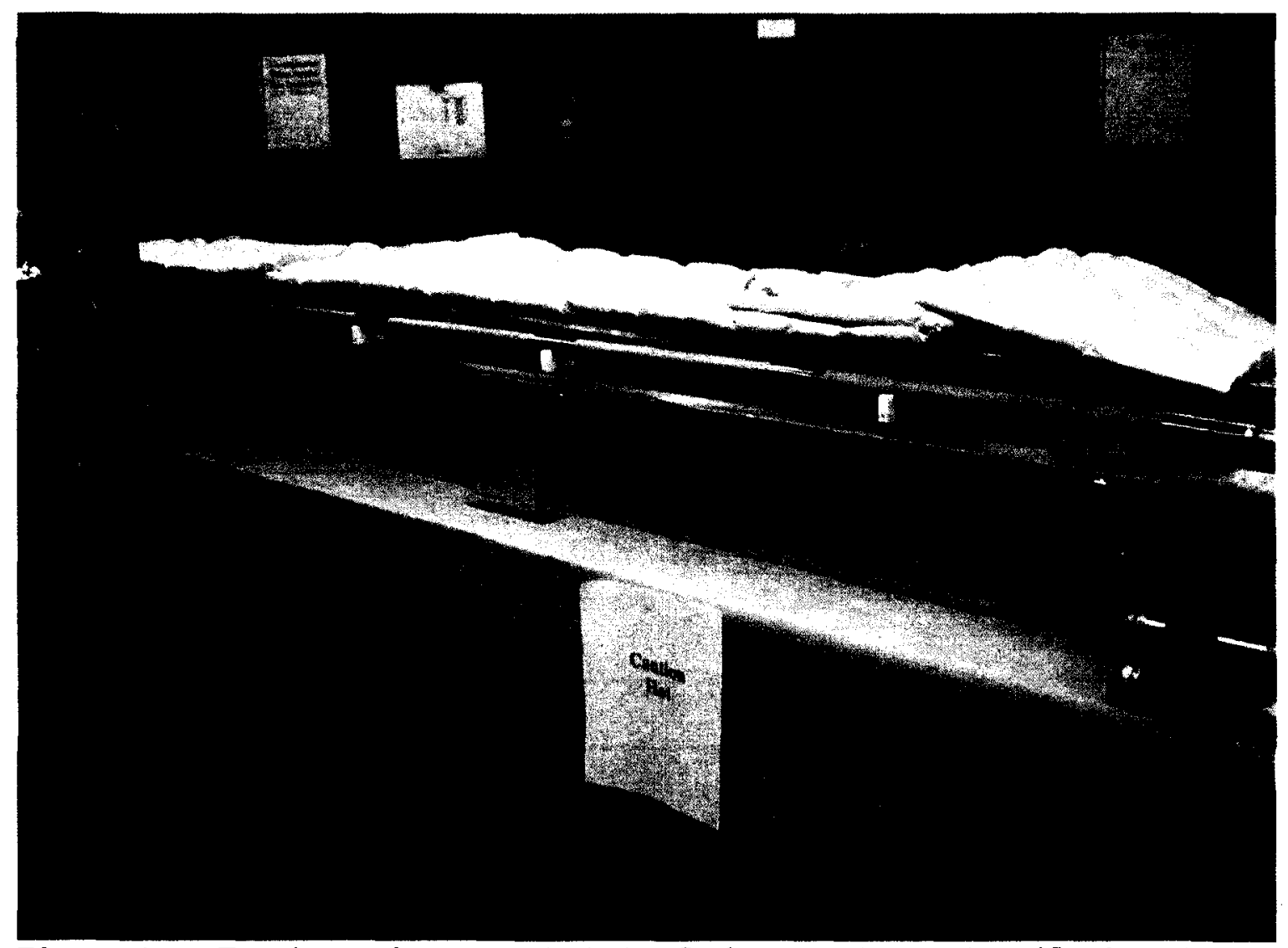

Picture 1. D-Zero beam pipe assembly during final preparations and certification of readiness. Kapton insulation can be seen on the Be pipe itself. Thermocouple wiring runs along a channel which supports the assembly. 
R. Rucinski

Feb. 17, 2006

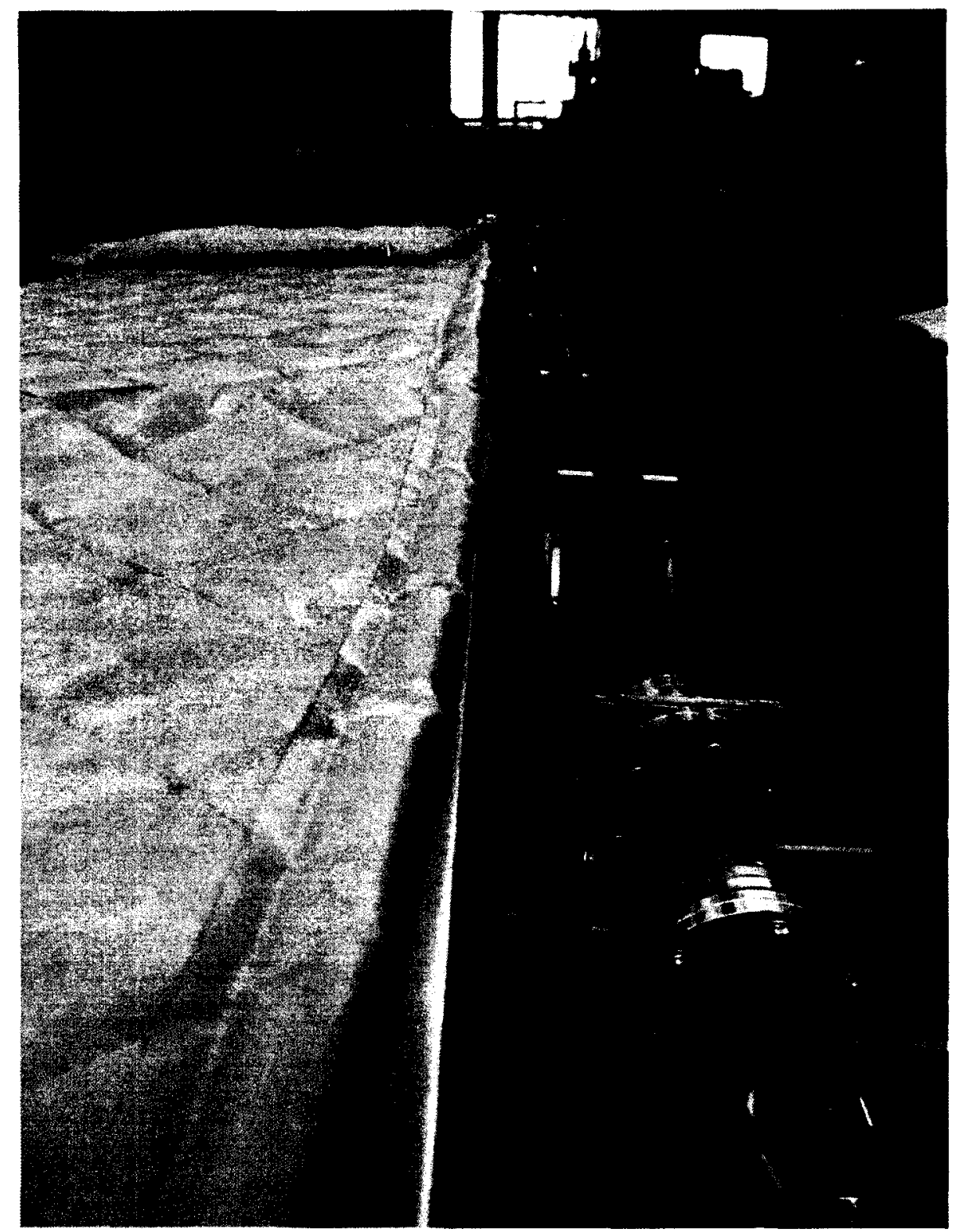

Picture 2. D-Zero beam pipe assembly. The ion gage in the foreground is attached to the end of the beam pipe extension. The exterior surface of the beam pipe extension and ion gage are discolored from previous higher temperature vacuum bakes. 


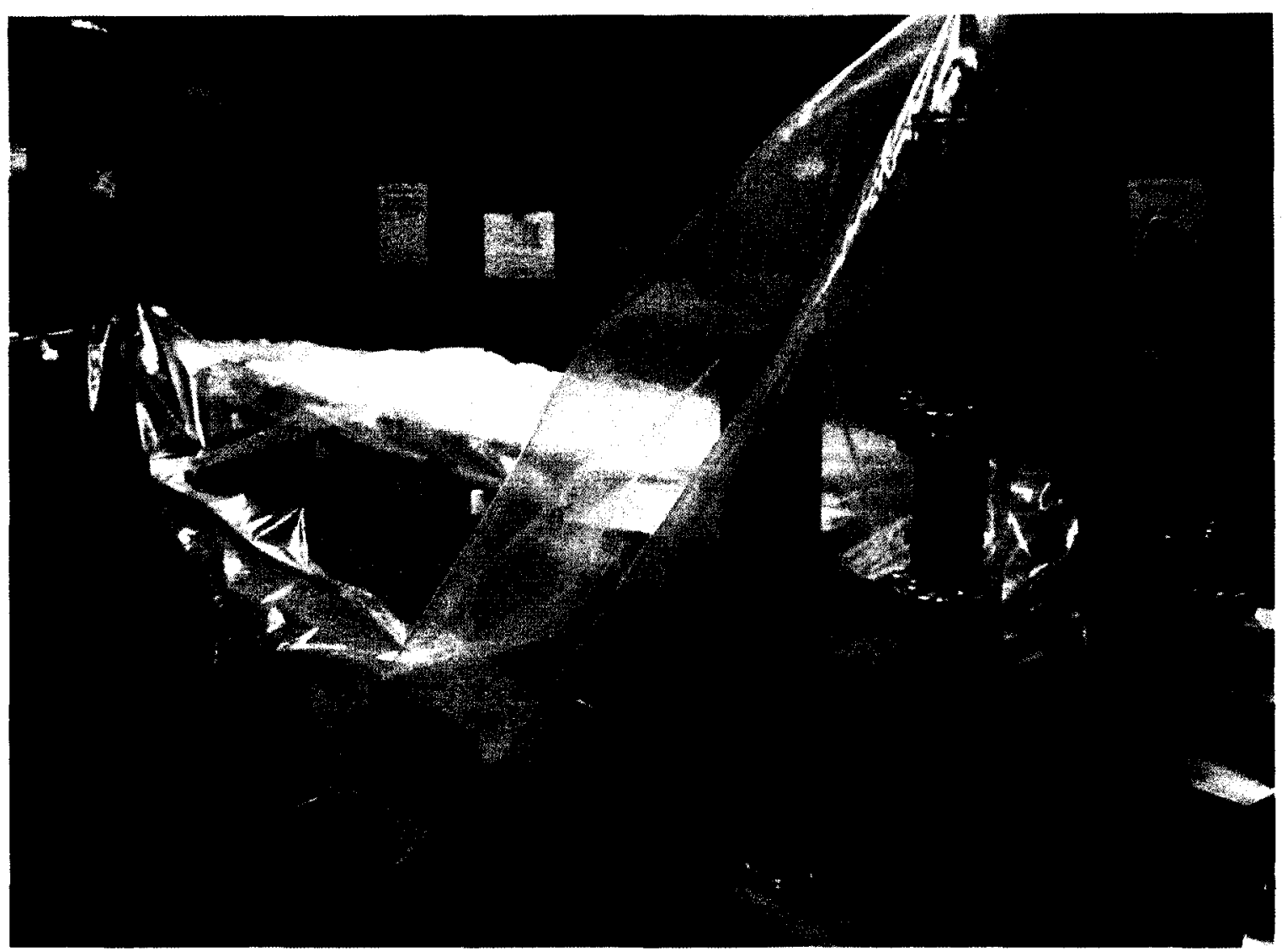

Picture 3. Instrumentation end of the beam pipe assembly. The RGA head is vertical in the foreground. The flex hose in the background, right hand side connects the metal seal valve and valve to the throat of the turbomolecular cart. The plastic tent was flooded with helium during the helium leak check. No response was seen.

\section{Beam pipe extensions}

Leak check, cleaned, assembled end to end.

Leak checked okay, sensitivity $=2.2 \times 10^{-10} \mathrm{~atm}-\mathrm{cc} / \mathrm{sec}$

Room temperature ultimate pressure $(24 \mathrm{hrs}$ pumping $)=2.6 \times 10^{-7} \mathrm{Torr}$

Baked to $350 \mathrm{C}$ (higher at some locations) for 45 hours.

Final pressure at $350 \mathrm{C}=4.1 \times 10^{-7}$ Torr

Final pressure after cooling to room temperature $=2.8 \times 10^{-7}$ Torr

Note: A leak detectable with the HMSLD developed at a flange joint after cooling to room temperature.

\section{Beryllium beam pipe assembly with extensions attached}

An ion gage is located on the dead (non pump) end of the assembly. This ion gage pressure is what was recorded and displayed on graphs that follow. Thermocouple temperature sensors were located in the air space next to the beryllium pipe and were recorded. Copper gaskets were used at the knife edge flange joints.

A Dupont leak detector (FNAL property number 90620) was used. It was checked for sensitivity to a calibrated leak. Two detectable leaks at flange joints were fixed prior to 
the passing leak check. The leak check was performed at a pressure of $1.0 \times 10^{-5} \mathrm{Torr}$ just after assembly. The leak detector background was 4 on the 1 scale. No leak response was seen during the leak check. A plastic sheet was placed over the assembly (see picture 3) and helium sprayed heavily underneath. No response was seen. To check sensitivity, a $4.0 \times 10^{-7} \mathrm{~atm}-\mathrm{cc} / \mathrm{sec} \mathrm{He}$ calibrated leak gave a 1000 division response, hence the sensitivity to seeing a 1 division response on the 1 scale was $4 \times 10^{-10} \mathrm{~atm}$ $\mathrm{cc} / \mathrm{sec}$.

The assembly was pumped down overnight down to $2.6 \times 10^{-7}$ Torr. See figure 1 for the pump down curve.

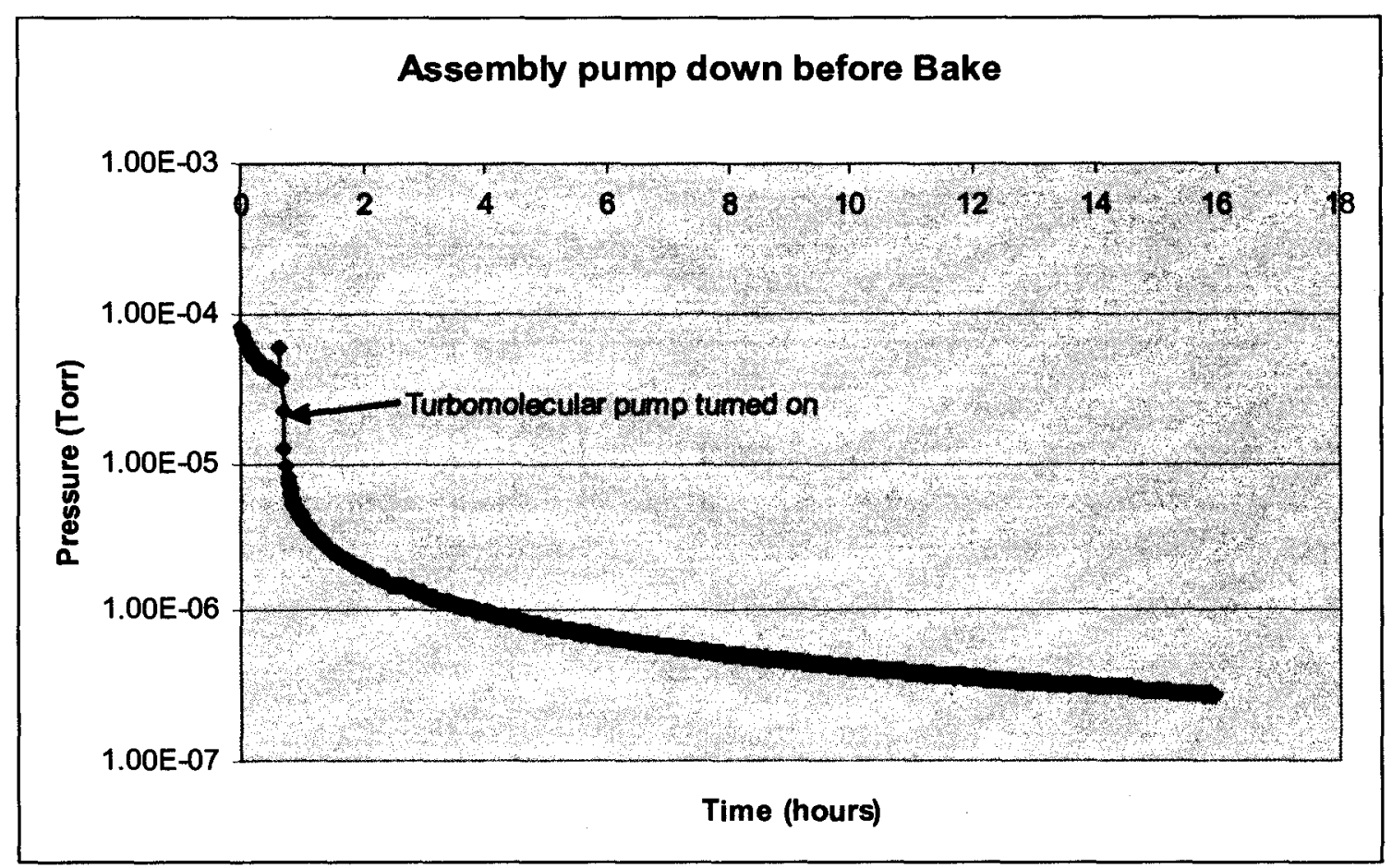

Figure 1. Pump down curve for beam pipe assembly at room temperature. The ultimate pressure $=2.6 \times 10^{-7}$ Torr after 16 hours of pumping overnight.

A rate of rise was performed on the assembly by closing a metal seal valve located on the instrumentation tee. Components included in the rate of rise include the beryllium beam pipe, two beam pipe extensions, two flange adapters $2 \mathrm{~A}$ style flange to conflat flange, the ion gage, a tee, an elbow, and the RGA head. Starting pressure was $2.6 \times 10^{-7}$ Torr. There was an initial jump to $1.4 \times 10^{-6}$ Torr when the valve was closed. The test was ended 15 minutes later at a pressure of $1.2 \times 10^{-4}$ Torr. See figure 2 for the rate of rise pressure versus time curve. The estimated volume and surface area of the components is 3.2 liters and $1090 \mathrm{~cm}^{2}$. The calculated outgassing rate for this test (after 16 hours pumping) is $4.9 \times 10^{-10}$ Torr- $\mathrm{L} / \mathrm{s}-\mathrm{cm}^{2}=6.5 \times 10^{-7} \mathrm{~W} / \mathrm{m}^{2}$. The outgassing value after baking and much more pumping time was 2 orders of magnitude less. 


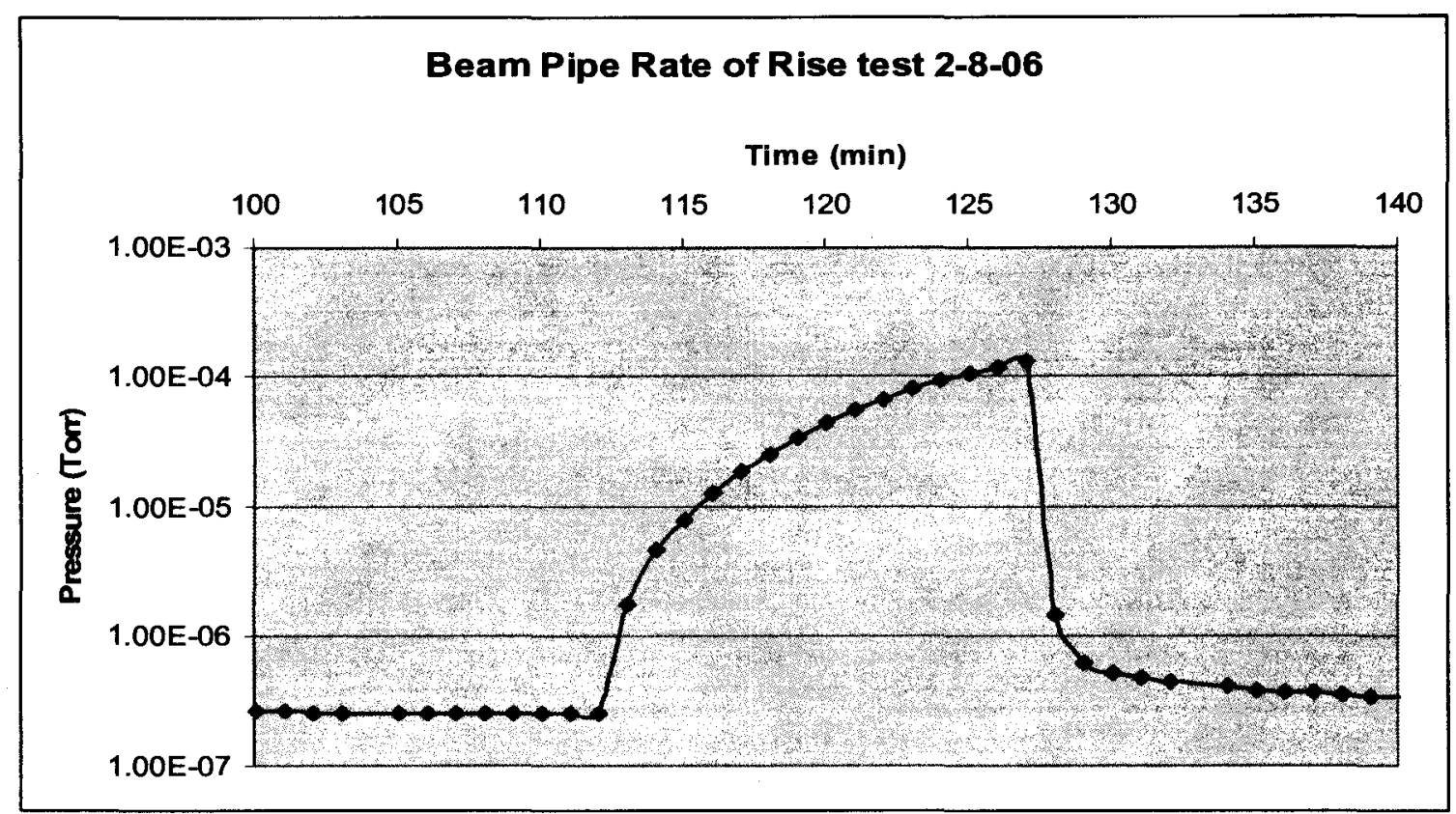

Figure 2. Pressure rate of rise test prior to the bake out.

Pumping was re-established after the rate of rise. An additional 20 hours of pumping brought the pressure down to $1.2 \times 10^{-7}$ Torr. The assembly was then let up to dry gaseous nitrogen and isolated. It was then moved inside a stainless steel heating pipe. Many precautions were taken with the heater controls and set up to protect the assembly. Details about these precautions appear later in this note. The assembly was hooked back up to the pumping system and a leak check with the DuPont leak detector was made. The heaters were turned on and the assembly was baked at $105 \mathrm{C}$ for 28 hours. See figure 3 for the pressure versus time curve. The worst pressure at the start of the heating period was $1.0 \times 10^{-5}$ Torr.

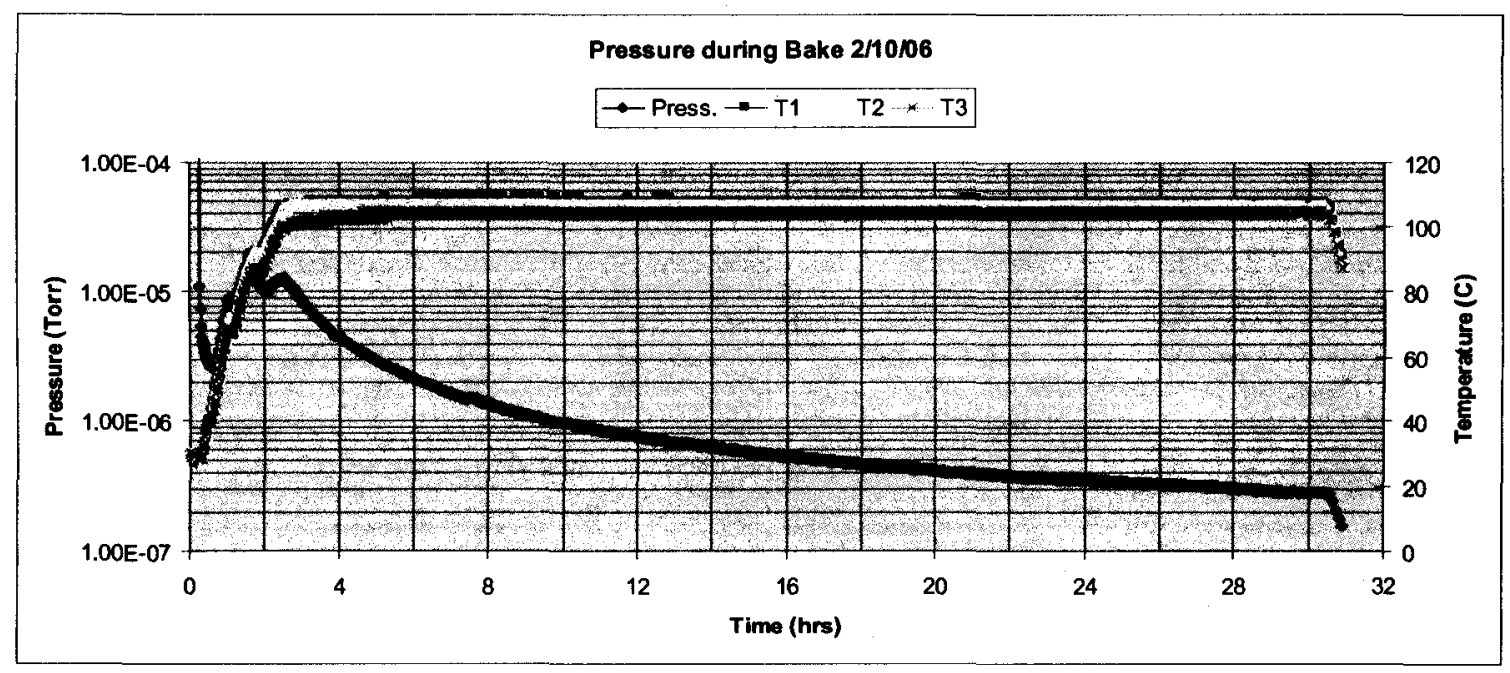

Figure 3. Vacuum pressure and temperature during the $105 \mathrm{C}$ bake period. 
The final pressure at $105 \mathrm{C}$ (and still decaying slightly) was $2.8 \times 10^{-7}$ Torr. From the decay curve, I estimated that the ultimate would be just under $2 \times 10^{-7}$ Torr if the heating and pumping was continued. A decision was made not to continue heating and pumping over the weekend since we were close to achieving the ultimate pressure. Figure 4 shows the pressure and temperatures during and after the assembly was cooled to room temperature. The room temperature ultimate pressure $(60 \mathrm{hrs}$. after the bake ended $)=1.2$ $\times 10^{-8}$ Torr

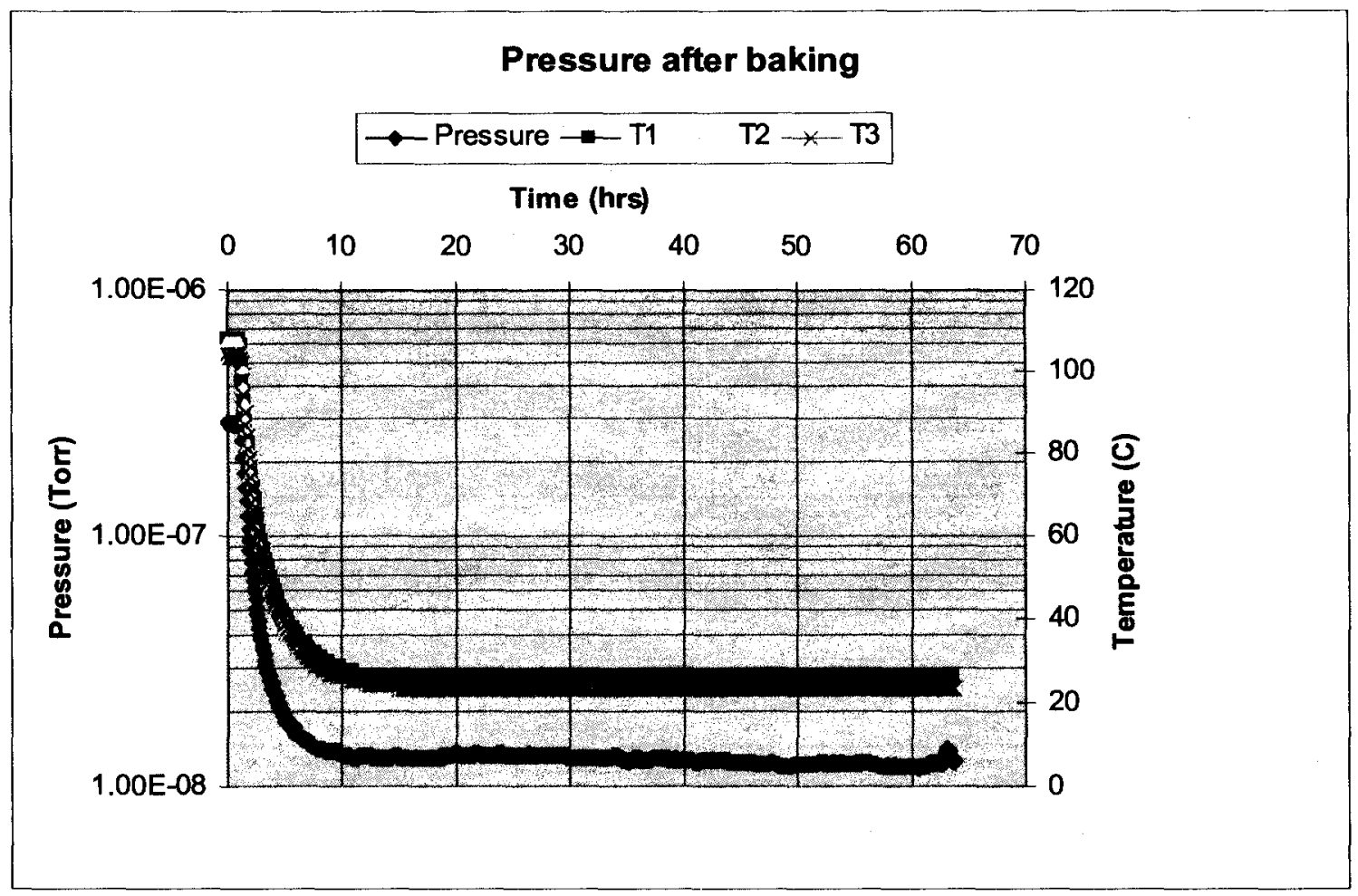

Figure 4. Pressure and temperature after the heater was turned off

An RGA analysis was done on the isolated assembly. Notable peaks indicate contributions from water (peak at 18), carbon monoxide (28), and carbon dioxide (44). The peak at a mass 2 is believed to be noise. Several RGA scans were run with and without the ion gage on. It is believed that the peak for $\mathrm{CO}(28)$ and $\mathrm{CO} 2$ (44) can be attributed to the filament of the RGA. This effect has been seen before. These peaks are abnormally high because there was no pumping during the RGA scan. RGA scans were also run after flooding the heater pipe with helium and no peak at the helium mass was seen. 


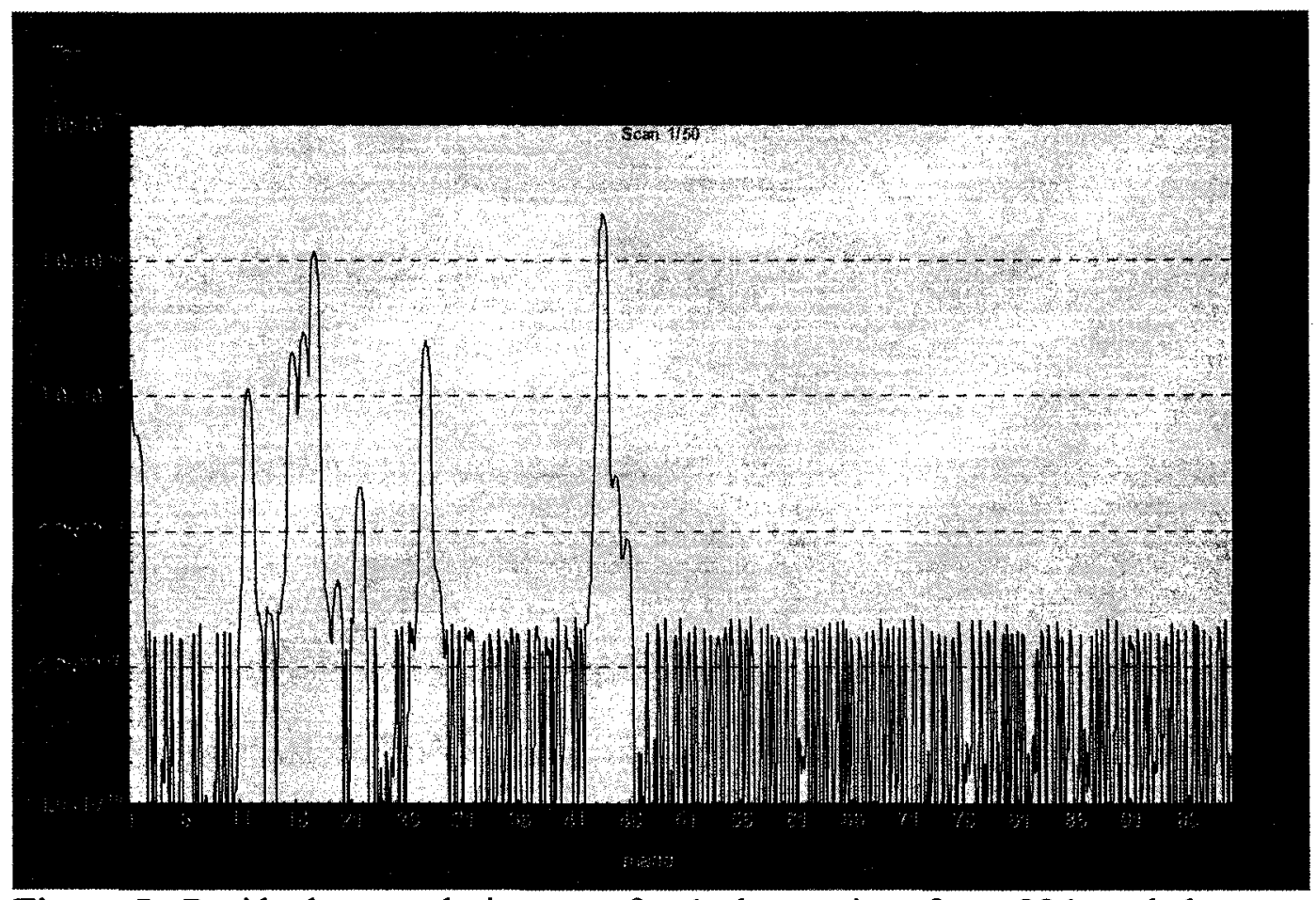

Figure 5. Residual gas analysis report for the beam pipe after a 28 hour bake.

A rate of rise was performed on the baked assembly. See figure 6 for the pressure versus time curve. The starting pressure was $2.0 \times 10^{-8}$ Torr. The pressure rise was very slow. The turbo pump was double isolated during the test so we are certain no pumping was occurring. After 40 minutes, the pressure rose to the next pressure decade, $1.0 \times 10^{-7}$ Torr. The calculated outgassing rate for this test was $9 \times 10^{-14}$ Torr-L/s-cm $\mathrm{cm}^{2}=1.2 \times 10^{-10} \mathrm{~W} / \mathrm{m}^{2}$. These values compare favorably to tables in vacuum books for metal surfaces.

During the rate of rise test on the assembly, the ultimate of the turbo pump was determined by reading an ion gage located at the throat of the turbo molecular pump. The pressure remained at $1.0 \times 10^{-9}$ Torr through out the test, evidently this is the ultimate of the pump. 


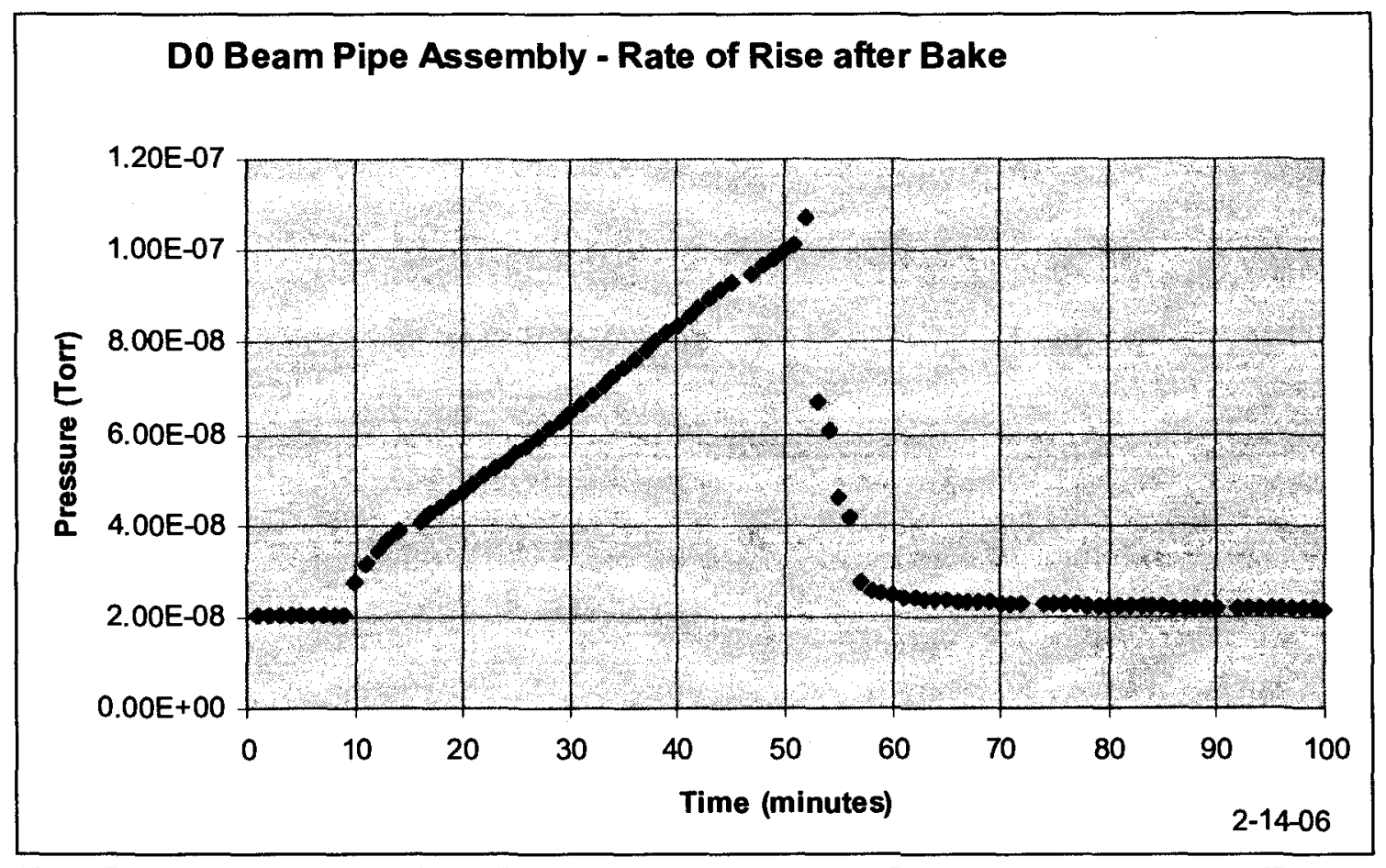

Figure 6. Pressure rate of rise curve.

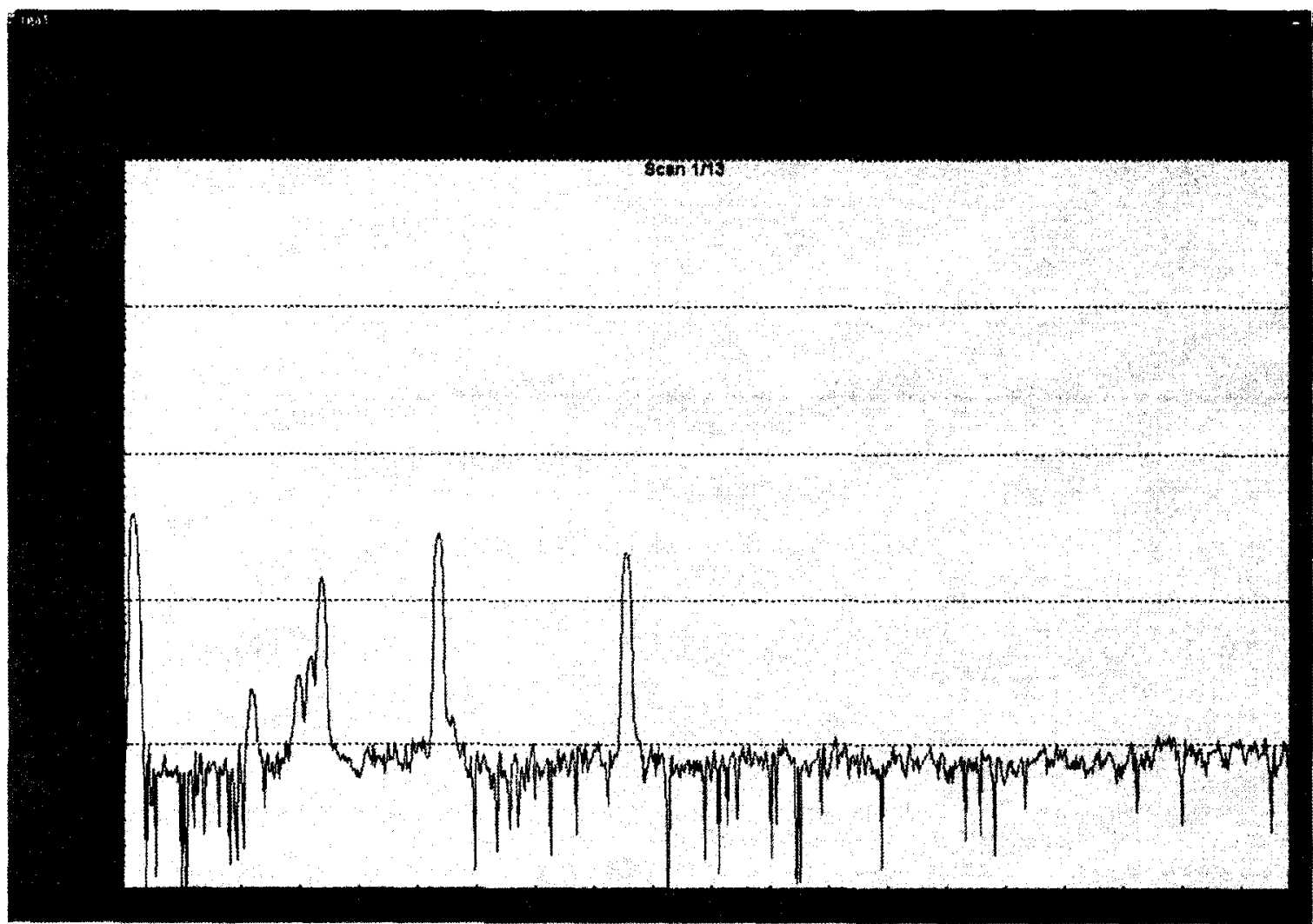

Figure 7. RGA analysis

\section{Conclusion}


R. Rucinski

Feb. 17, 2006

The Run $2 \mathrm{~B}$ beam pipe assembly is leak tight and conditioned so that it will provide minimal gas load in high vacuum service. It has been characterized and the information documented so that others can independently reach the same conclusion. 


\section{Reference material}

Reference: Job Hazard analysis and detailed procedure. Note, a deviation was made in that the beam pipe and extensions were checked/validated as an assembly rather than separately.

\section{PPD WORK PLAN / JOB HAZARD ANALYSIS}

JOB NAME: Vacuum bake out of D-Zero Run 2B Be pipe at the Proton Assembly Building

LOCATION: Proton Assembly Building

ESTIMATED DATES OF OPERATION: November 2005

DESCRIPTION OF WORK: Vacuum bake out and final preparations of D-Zero Run 2B Be pipe

\section{General Hazards:}

The run $2 \mathrm{~B}$ pipe is a critical component of the DZero upgrade. It cannot be readily repaired or replaced if damaged. Hence, it is critical to the mission of the laboratory.

The run $2 \mathrm{~B}$ pipe is delicate. It is a very thin wall beryllium tube, 0.020 " thick with stainless steel end flanges, 72" in overall length. The pipe must be handled and protected so that it is not bumped, dropped, or otherwise subject to harm. For example, a $2 \mathrm{lbf}$ concentrated point load on the tube's side wall or a $3 \mathrm{lbf}$ cantilevered load results in unacceptable stress levels (1/3 of yield stress). Also, dropping any object such as a wrench or vacuum fitting from any height onto the pipe could also lead to consequential damage.

The stainless steel end flanges brazed to the beryllium tube have a machined knife edge seal as a leading feature. Accidental contact to the end of the pipe could damage the knife-edge. This would be difficult to repair and could compromise the high vacuum seal needed at the D-Zero interaction region (at installation).

The pipe is constructed of beryllium. Beryllium is a special toxic hazard (FESHM 5025.5). Note that ES\&H took wipes of the external pipe surface. ES\&H reported the Be wipe results on Sept. 15, 2005. "...the Be pipe is well below the Fermilab standards for removable Be. The standard is $0.025 \mathrm{ug} / \mathrm{cm}^{\wedge} 2$ removable $\mathrm{Be}$, the highest reading was $0.014 \mathrm{ug} / \mathrm{cm}^{\wedge} 2$. Care must still be taken when handling the $\mathrm{Be}$ pipe. Handle with nitrile gloves."

The internal volume of the run $2 \mathrm{~B}$ pipe is designed to be a high vacuum component and must be kept clean of contamination such as hand oils, moisture, body fluids, etc. The internal beryllium surface is uncoated and will readily corrode in the presence of water. A dry gas nitrogen purge should be maintained internally (and externally) whenever possible. 
JHA TABLE (See detailed procedure that follows for details)

\begin{tabular}{|c|c|c|}
\hline Step/Phase of Job & Safety Hazard & $\begin{array}{l}\text { Precautions/Mitigation of } \\
\text { Hazard }\end{array}$ \\
\hline $\begin{array}{l}\text { 1.1 Carefully remove the purge } \\
\text { pipe with the carrier pipe and } \mathrm{Be} \\
\text { pipe inside it from the crate and } \\
\text { place it on the table. } \\
\text { 1.2. Remove the carrier pipe with } \\
\text { the Be pipe inside of it from the } \\
\text { purge pipe. } \\
\text { 1.3. Remove the Be pipe from the } \\
\text { carrier pipe, remove the sleeve } \\
\text { and place it in the support cradle. }\end{array}$ & $\begin{array}{l}\text { 1.1 Damage to valuable object. } \\
\text { 1.2. Damage to valuable object. } \\
\text { 1.3. Damage to valuable object. } \\
\text { Contact with beryllium } \\
\text { object. }\end{array}$ & $\begin{array}{l}\text { 1.1 The run } 2 \mathrm{~B} \text { pipe is } \\
\text { reasonably well protected } \\
\text { inside the carrier pipe. A } \\
\text { thin foam strip cushions the } \\
\text { ends and radial motion. Do } \\
\text { not drop the carrier pipe. } \\
\text { Hand carry it horizontally. } \\
1.2 \text { Use extreme care when } \\
\text { handling. } \\
1.3 \text { Use extreme care when } \\
\text { handling. Wear nitrile } \\
\text { gloves. }\end{array}$ \\
\hline $\begin{array}{l}\text { 2.1. Attach the ion gauge and } \\
\text { adapter to one end of the Be pipe } \\
\text { using a copper gasket. } \\
2.2 \text {. Attach the pump out adapter } \\
\text { to the other end of the pipe using } \\
\text { a copper gasket. }\end{array}$ & $\begin{array}{l}2.1 \text { The stainless steel end } \\
\text { flanges brazed to the beryllium } \\
\text { tube have a machined knife } \\
\text { edge seal as a leading feature. } \\
\text { Accidental contact to the end of } \\
\text { the pipe could damage the } \\
\text { knife-edge } \\
\text { 2.2. The stainless steel end } \\
\text { flanges brazed to the beryllium } \\
\text { tube have a machined knife } \\
\text { edge seal as a leading feature. } \\
\text { Accidental contact to the end of } \\
\text { the pipe could damage the } \\
\text { knife-edge }\end{array}$ & $\begin{array}{l}\text { 2.1. Use extreme care when } \\
\text { attaching items to the knife edge } \\
\text { flanges. } \\
2.2 \text {. Use extreme care when } \\
\text { attaching items to the knife edge } \\
\text { flanges. }\end{array}$ \\
\hline $\begin{array}{l}\text { 3.1 Attach thermocouples to both } \\
\text { ends and the middle of the Be } \\
\text { pipe. } \\
\text { 3.2. Place the Be pipe inside the } \\
\text { heating tube. }\end{array}$ & $\begin{array}{l}\text { 3.1. Damage to valuable object. } \\
\text { Contact with beryllium object. } \\
\text { 3.2. Damage to valuable object. } \\
\text { Contact with beryllium object. }\end{array}$ & $\begin{array}{l}\text { 3.1. Use extreme care when } \\
\text { handling. Attach thermocouples } \\
\text { without mechanical force or pipe } \\
\text { surface contamination. Wear } \\
\text { nitrile gloves. } \\
\text { 3.2. Use extreme care when } \\
\text { handling. Wear nitrile gloves. }\end{array}$ \\
\hline $\begin{array}{l}\text { 4.1. Attach a pumping manifold } \\
\text { to the pump out adapter and } \\
\text { secure the manifold to the table. }\end{array}$ & $\begin{array}{l}\text { 4.1. Damage to valuable object. } \\
\text { Putting stress on } \mathrm{Be} \text { pipe. }\end{array}$ & $\begin{array}{l}\text { 4.1. Use a flexible hose between } \\
\text { the pump out adapter and the } \\
\text { manifold. Secure the manifold to } \\
\text { the table. }\end{array}$ \\
\hline $\begin{array}{l}5.1 \text { Bake the Be pipe at } 105 \mathrm{C} \text { for } \\
\text { a period of } 24 \text { hours. }\end{array}$ & 5.1. Damage to valuable object. & $\begin{array}{l}5.1 \text { Keep vacuum pressure below } \\
1 \mathrm{E}-4 \text { torr. An electrical ground } \\
\text { path (other than through the } \\
\text { vacuum pumping equipment and } \\
\text { Be pipe) should be provided for } \\
\text { protection against a heater short } \\
\text { to the container. A heater } \\
\text { controller is used to regulate the } \\
2 \mathrm{~B} \text { pipe temperature. A klixon or } \\
\text { other over temperature protection } \\
\text { should be provided. The bake out } \\
\text { should not be left unattended }\end{array}$ \\
\hline $\begin{array}{l}\text { 6.1 Backfill the Be pipe with dry, } \\
\text { gaseous nitrogen. }\end{array}$ & $\begin{array}{l}\text { 6.1. Damage to valuable object. } \\
\text { 6.2. Damage to valuable object. }\end{array}$ & $\begin{array}{l}\text { 6.1. Protect against } \\
\text { overpressurization. }\end{array}$ \\
\hline
\end{tabular}


6.2. Remove the Be pipe from the heating tube.

6.3. Place the Be pipe inside the carrier pipe.

6.4 Place the carrier pipe inside the purge pipe.

6.5 Place the purge pipe back into the crate.
6.2. Use extreme care when handling. Wear nitrile gloves. 6.3. Use extreme care when handling. Wear nitrile gloves. 6.4. Use extreme care when handling.

6.5. Use extreme care when handling. 


\section{DETAILED PROCEDURE}

1. Carefully remove the purge pipe with the carrier pipe and Be pipe inside it from the crate and place it on the table.

2. Remove the carrier pipe with the Be pipe inside of it from the purge pipe.

3. Remove the Be pipe from the carrier pipe, remove the sleeve and place it in the support cradle.

4. Attach an ion gauge and adapter to one end of the Be pipe using a copper gasket. Extension pieces were attached to the Be pipe so the assembly could be characterized together as a unit. 2/15 R. Rucinski

5. Attach the pump out adapter to the other end of the pipe using a copper gasket.

6. Attach thermocouples to both ends and the middle of the Be pipe. Hold the temperature sensors to the beam pipe by a method that does not apply significant force to the pipe and will not be difficult to remove. If tape is used, do not attach the tape to the pipe surface, instead use a sleeve that can be removed afterwards. Note that the surface of the beryllium pipe is coated with a non-durable Beryl coat D coating that can be compromised if subject to abrasion.

Comment: Thermocouples were located in the air space next to the beryllium pipe, not physically attached, 2/15 R.Rucinski

7. Place the Be pipe inside the heating tube.

8. Attach a pumping manifold to the pump out adapter and secure the manifold to the table. Vacuum hose and connection equipment should be in good clean condition.

9. Attach a dry rougher/turbo system to the manifold.

10. Attach an RGA to the manifold.

11. Attach an HMSLD with a cold trap to the manifold.

12. Vacuum pump run 2B beryllium beam pipe at room temperature to less than $5 \mathrm{E}-5$ Torr. Notes: Use either dry vacuum pumping system or LN2 cold trapped system with auto shut off valve in case of power loss. If unable to get the run $2 \mathrm{~B}$ beryllium beam pipe below $5 \mathrm{E}-5$ Torr, diagnose problem by leak checking and/or a valved off rate of pressure rise. Record the vacuum pressure and time at least every 3 hours during the pump down to an ultimate vacuum pressure. Ideally a chart recorder for vacuum pressure versus time will be used.

13. Perform a leak check. Correct any leaks such that no detectable leaks are detected. The leak detector shall be on the most sensitive scale of a helium leak detector with a minimum sensitivity of $10 \mathrm{E}-9 \mathrm{~atm}-$ $\mathrm{cc} / \mathrm{sec} \mathrm{He}$. Use a chart recorder on the signal output and annotate background, test with calibrated leak, and leak checking period.

14. Perform a room temperature rate of rise test over at least one decade of pressure change. Notes: Record the pressure, and allow the pressure to rise to at least 1 decade higher pressure. Record the pressure and time frequently during the test. Ideally a chart recorder for vacuum pressure versus time will be used. The outgassing rate per unit surface area can be calculated: $Q=$ Volume * [Pfinal - Pstart] $] /[$ Time of test)*(Surface Area)]. Units will be Torr-L/s-cm^2. Consult with the engineer (Russ Rucinski) before proceeding to the next step.

15. Bake the Be pipe at $105 \mathrm{C}$ for a period of 24 hours. A klixon or other over temperature protection should be provided. An electrical ground path (other than through the vacuum pumping equipment and $2 \mathrm{~B}$ pipe) should be provided for protection against a heater short to the container. With active pumping, the $2 \mathrm{~B}$ pipe should be at $105 \mathrm{C}$ and $<10 \mathrm{E}-4$ Torr for a 24 hour period. Provide a record of temperature and 
pressure at least every 3 hours during the bake out. Bake out should not be unattended. (PPD/MD/D0 Ops can provide personnel for overnight coverage).

Actual precautions taken, 2/15 R.Rucinski: Here is a summary of heater protection controls. We have an overtemperature controller set at $115 \mathrm{C}$ in series with the temperature controller. We have three Klixons with a nominal value of $120 \mathrm{C}$ (tested trip point of $116 \mathrm{C}$ ) that will be located along the pipe which will be in series with the temperature controller output. We are also using a Variac which will limit the power available to the heat tape. The heat tape is wrapped on the outside of an independently grounded pipe. The beam pipe assembly resides inside the air space of the heated pipe with thermocouples for monitoring (three) and control (two) in the air space next to the pipe. We will be present while the assembly comes up to steady state. My operations technicians will visit the baking area every 3-4 hours during the night. The ops techs will also remotely watch the three non-control temperatures as displayed back at D-Zero.

16. After the bake out and a cooling period to room temperature, perform a leak check. No detectable leaks on the most sensitive scale of a helium leak detector with a minimum sensitivity of $10 \mathrm{E}-9 \mathrm{~atm}-\mathrm{cc} / \mathrm{sec}$ He. Use a chart recorder on the signal output and annotate background, test with calibrated leak, and leak checking period. Actual: A final leak check was done by flooding the heater pipe with helium and seeing no response on the RGA. Also the rate of rise was so good that it is evident no leaks were present. $2 / 15 R$. Rucinski

17. Perform a residual gas analysis of the Be pipe and print out the results.

18. Perform a room temperature rate of rise test over at least one decade of pressure change. Notes: Record the pressure, and allow the pressure to rise to at least 1 decade higher pressure. Record the pressure and time frequently during the test. Ideally a chart recorder for vacuum pressure versus time will be used. The outgassing rate per unit surface area can be calculated: $Q=$ Volume * [Pfinal - Pstart $] /[$ (Time of test)*(Surface Area)]. Units will be Torr-L/s-cm^2. Consult with the engineer (Russ Rucinski) before proceeding to the next step.

19. Prepare carrier pipe and purge pipe. Notes: Stamp or brass tag one end of the carrier pipe and purge pipe "Braze repair/kink end" to correspond to the orientation of the run 2B pipe that will eventually reside within it. Place pipes inside an appropriately sized vacuum pipe/tube. Pump vacuum pipe/tube with a dry rougher/turbo. Heat the vacuum pipe/tube (and contents by conduction) to a temperature of $120 \mathrm{C}$ for 8 hours. After cooling, back fill vacuum pipe with dry, gaseous nitrogen.

20. Backfill and store the $2 \mathrm{~B}$ pipe. Notes: Backfill the run $2 \mathrm{~B}$ beryllium beam pipe with clean dry gaseous nitrogen to one atmosphere of pressure. Provide protection against over pressurizing by having a low pressure relief or having an unbolted vacuum flange connection. With a purge source provided on the pumping side, disconnect the downstream connections from the run 2B beryllium pipe so that it can be slid out of the baking pipe. Expose the beryllium pipe for removal of the thermocouple sensors. Then safely slip the carrier pipe over the beryllium pipe making sure the "Braze repair/kink end" orientation matches. When only a few inches of the beam pipe are left, disconnect the vacuum pumping/purge supply connection from the beryllium pipe. Promptly but safely insert the run $2 \mathrm{~B}$ pipe the rest of the way into the carrier pipe. Lightly hand tighten the cap onto the end of the carrier pipe. Close the ends of the purge pipe around the carrier pipe and maintain purge flow. Place the run 2B beryllium pipe which resides inside the $11 / 4$ " carrier pipe which resides in the 2 " tube purge pipe into the foam lined blue Brush Wellman crate. Transport the crate to DZero assembly building, maintaining and monitoring the dry nitrogen purge until installation. 
TASK SUPERVISOR: Cary Kendziora: x3176, LDP 630-732-3408

RESPONSIBLE ENGINEER: Russell Rucinski: x2888, LDP 630-218-3927

\section{TEAM MEMBER NAMES (SIGN CLEARLY)}

I have reviewed this Work Plan and Hazard analysis. I understand the hazards and required precautionary actions. I will follow the requirements of this plan or notify my supervisor if I am unable to do so.

Name (print) ID\# $\quad$ Signature

Date

RON DAVIS

MARK RUSCHMAN

RUSSELL RUCINSKI

JIM FAGAN

CARY KENDZIORA (Task Supervisor)

PREPARED BY:

(Mark Ruschman \& Russell Rucinski) DATE:

APPROVED BY: (L0 Mechanical Installation Coord. W. E. Cooper)DATE:

APPROVED BY: (D0 Technical Integration Coord. G.Ginther)

DATE:

APPROVED BY: (PPD/MD Dept. Head, K.Krempetz)

DATE:

APPROVED BY: (PPD ES\&H SSO, M.Heflin)

DATE:

\section{NOTIFICATION of PPD Div Head}

